Letrônica, Porto Alegre, v. 7, n. 1, p. 86-112, jan./jun., 2014

\title{
MEMORIZAÇÃO DE SENTENÇAS COM CONSTRUÇÃO ESPECÍFICA DE UMA DAS LÍNGUAS DE BILÍNGUES
}

\author{
SENTENCE MEMORIZATION WITH A LANGUAGE-SPECIFIC \\ CONSTRUCTION BY BILINGUALS
}

\begin{abstract}
Ricardo Augusto de Souza*
Resumo: Neste trabalho revisitamos a hipótese da regeneração, que traz uma proposta sobre a natureza do mecanismo psicolinguístico que dá suporte à rememoração imediata de sentenças ouvidas ou lidas, em memória de curta duração. 0 artigo apresenta uma hipótese sobre a memorização de sentenças por bilíngues derivada dos pressupostos da hipótese da regeneração, segundo a qual os mecanismos de produção de sentenças novas operam também na memorização imediata de sentenças. 0 artigo relata um estudo no qual se buscou examinar a acessibilidade de representações sintáticas licenciadas em apenas uma das línguas dos bilíngues no processamento da outra. Os resultados apontam para tal acessibilidade durante a produção de sentenças memorizadas, porém somente entre bilíngues com alta proficiência.

Palavras-chave: Hipótese da regeneração; Memorização de sentenças; Bilinguismo; Estrutura argumental.

Abstract: This paper revisits the regeneration hypothesis, a proposal about the nature of the psycholinguistic mechanism that supports the immediate recall of sentences recently heard or read. We present a hypothesis about sentence recall in bilinguals, which is based on the assumptions of the regeneration hypothesis. According to the hypothesis, the mechanisms of new sentence production also operate in immediate sentence recall. We address such hypothesis with a study that aimed to investigate the accessibility to language-specific syntactic representations while bilinguals process another language. Results suggest there is such access to language-specific representation, but only for highly proficient bilinguals.
\end{abstract}

Keywords: Regeneration hypothesis; Sentence recall; Bilingualism; Argument structure.

\footnotetext{
${ }^{*}$ Doutor em Linguística Aplicada. Professor Associado da Faculdade de Letras da Universidade Federal de Minas Gerais. Docente do Programa de Pós-Graduação em Estudos Linguísticos, com atuação em linha de pesquisa em processamento da linguagem. 0 autor agradece à Coordenação de Aperfeiçoamento de Pessoal de Nível Superior (CAPES) pela bolsa BEX4087-10-0 e à Fundação de Amparo à Pesquisa do Estado de Minas Gerais pela bolsa APQ02204-12, que financiaram este trabalho.
} 


\section{Introdução}

A natureza da arquitetura do repositório de representações linguísticas na mente bilíngue é um dos problemas relevantes dentro da pesquisa em psicolinguística do bilinguismo. Especificamente, nessa vertente de investigação busca-se delimitar o quanto é possível haver integração entre representações de línguas específicas na mente bilíngue, para assim especificar em quais âmbitos de organização e do desempenho linguístico tal integração seria possível. 0 exame dessas questões pode conduzir à maior compreensão dos mecanismos de processamento da linguagem natural, através do que é revelado sobre eles na situação bilíngue. Mais ainda, trata-se de questões com claras interfaces com a teoria linguística, uma vez que podem conduzir à delimitação do quão precocemente determinísticos e estáveis, ou o quão subespecificados e maleáveis à experiência linguística, devem ser modelos da faculdade da linguagem. Trata-se, portanto, de um problema de interesse não apenas para os modelos de capacidade de processamento da linguagem por bilíngues, mas também potencialmente de interesse para modelos teóricos sobre a caracterização cognitiva da linguagem humana.

Há alguma convergência geral nos estudos sobre a organização do léxico bilíngue que sugerem repositórios de representações lexicais razoavelmente integrados. Não obstante, há ainda debates sobre o quão prevalente é tal integração nos estágios de aquisição bilíngue, ou se ela é uma função específica dos altos níveis de proficiência na L2 (BARTOLLOTI; MARIAN, 2013). Um nível de consenso bem menos expressivo, talvez associado a um volume menor de estudos, diz respeito à integração de representações sintáticas.

O presente trabalho tem por objetivo trazer uma contribuição para o avanço do debate sobre a arquitetura do repositório mnemônico de representações sintáticas interlinguais entre os bilíngues. Especificamente, buscaremos demonstrar como um modelo psicolinguístico sobre a memorização imediata de sentenças, a hipóteses da regeneração, pode oferecer hipóteses testáveis sobre a arquitetura das representações sintáticas bilíngues. Buscaremos, ainda, demonstrar como, a partir dos pressupostos de tal modelo psicolinguístico, uma tarefa experimental baseada na memorização de sentenças permitiu a operacionalização do construto da acessibilidade a uma construção 
sintática específica da segunda língua por falantes bilíngues do português do Brasil (PB) e do inglês, durante a produção de enunciados em sua primeira língua.

A sessão seguinte discutirá a hipótese da regeneração, segundo a qual a memorização imediata de sentenças envolve, no âmbito da memória de trabalho, os mesmos mecanismos da produção de enunciados novos. Em seguida, trataremos de uma construção de realização de estrutura argumental específica da língua inglesa e de evidências obtidas em tarefas de compreensão que justificam a hipótese de que tal construção é acessada por bilíngues do PB e do inglês durante o processamento na primeira língua. Passaremos então ao detalhamento dos métodos que geraram os dados do presente trabalho e dos critérios adotados para a análise ora apresentada, para em seguida detalharmos e discutirmos os resultados. 0 artigo culmina com conclusões sobre direções futuras para o tipo de estudo ora relatado.

\section{A memorização imediata de sentenças: revisitando os estudos de Potter e Lombardi}

A memorização imediata de sentenças é caracterizada pela manutenção perfeita, ou quase perfeita, dos componentes lexicais e sintagmáticos que dão suporte à expressão do conteúdo proposicional de uma sentença. Em outras palavras, a memorização imediata se caracteriza pela permanência na memória de uma "cópia mental" de uma sentença lida ou ouvida. Na memorização imediata, há uma reprodução altamente acurada de uma sentença lida ou ouvida imediatamente após a exposição inicial a ela. Trata-se, assim, de um efeito da capacidade da memória de trabalho, efeito este para o qual foram propostos, na literatura psicolinguística, dois modelos de descrição dos mecanismos principais envolvidos que se assentam em pressupostos distintos.

A primeira destas propostas, tal como revisto em Von Eckardt e Potter (1985), Potter e Lombardi (1990), Lombardi e Potter (1992) e Potter e Lombardi (1997), era de que na memorização imediata uma representação total da forma de superfície de uma sentença seria mantida na memória dos falantes. Portanto, tal como comentado em Potter e Lombardi (1990), o pressuposto era que o mecanismo envolvia a armazenagem 
completa de uma sequência de representações fonético-fonológicas e/ou grafêmicas, em uma cópia mental verbatim da sentença memorizada (p. 634).

Especificamente, segundo Potter e Lombardi (1990), a proposta da cópia mental verbatim como mecanismo da memorização imediata de sentenças não atribuía qualquer papel crítico à representação semântica, ainda que fosse aceito que tal representação estivesse presente na memória. A principal consideração que motivou os proponentes do mecanismo da cópia perfeita era que configurações semânticas não se mapeiam exclusivamente a uma única sequência e ordenação de itens lexicais. Tal ponderação, em si correta, pode ser prontamente verificada nas sentenças abaixo, onde duas ordenações distintas se mapeiam a uma única representação semântica básica, composta por um evento em tempo passado, aspecto perfectivo, e envolvendo os papéis semânticos de agente e tema.

(1) João lavou o carro na garagem.

(2) 0 carro foi lavado por João na garagem.

Não obstante, o papel de representações semânticas na memorização imediata de sentenças foi abordada nos trabalhos de Potter e Lombardi (1990), Lombardi e Potter (1992) e Potter e Lombardi (1997). Esses estudos propuseram uma alternativa à proposta da cópia mental verbatim como mecanismo psicolinguístico que dá suporte à memorização imediata de sentenças. Especificamente, nesses estudos são discutidos resultados experimentais interpretados como evidências contrárias à ideia de que a memorização imediata é sustentada por uma cópia da sentença ouvida ou lida na memória de trabalho. A partir desses resultados, as autoras propõem que há, no âmbito da memória de trabalho, uma reconstrução de sentenças lidas ou ouvidas a partir da manutenção de uma representação semântica das mesmas. Em outras palavras, as autoras propõem que nos eventos de rememoração de sentenças, as sentenças são reconstruídas na memória de curta duração. Esta proposta foi denominada pelas autoras de hipótese da regeneração.

Em Potter e Lombardi (1990) são relatados sete experimentos nos quais os participantes engajavam-se com tarefas que mesclavam a rememoração oral imediata de sentenças lidas com a tomada de decisão sobre a presença de uma palavra chave em uma lista de palavras. A manipulação crítica realizada nos experimentos das autoras era 
a apresentação, nas listas, de um sinônimo de uma das palavras das sentenças. As pesquisadoras mensuravam as incidências de intrusão dessas palavras sinônimas na rememoração oral das sentenças, sendo que a intrusão ocorreu com significância estatística nos experimentos. Potter e Lombardi (1990) sugerem que a explicação para o nível tipicamente alto de acurácia na memorização imediata de sentenças reside em tomá-la como função da alta ativação das unidades lexicais que compõem as sentenças lidas ou ouvidas, em eventos que requerem memória de curta duração. Não obstante, a atratividade de um potencial sinônimo indicia, na interpretação das autoras, que o mecanismo de reativação seja fortemente norteado por representações semânticas, mesmo quando se tratando de memória de curta duração.

Um desdobramento imediato da hipótese da regeneração é a noção de que tampouco haveria total estabilidade das representações sintáticas das sentenças lidas ou ouvidas em sua rememoração imediata. Esta questão foi colocada a teste nos quatro experimentos relatados em Lombardi e Potter (1992), cujo alvo foram sentenças com verbos bitransitivos que exprimem mudança de posse (ex.: dar, enviar, remeter, etc.) que participam ou não da alternância dativa, no inglês. A alternância dativa é uma construção que permite ao sintagma nominal ao qual se mapeia um argumento com papel semântico de recipiente ser sintaticamente realizado tanto como objeto de uma preposição quanto imediatamente após o verbo. No inglês, há pares de verbos quase sinônimos que se diferenciam pelo fato de apenas um dos verbos participar da alternância dativa. Ou seja, em relação à alternância dativa, há verbos bitransitivos do inglês que podem ser classificados ou como alternantes, ou como não alternantes. Este fato é exemplificado com sentenças (3) a (6) abaixo (adaptadas de LOMBARDI; POTTER, 1992, p. 714), que mostram tal contraste com o par give (dar) e donate (doar), no qual o primeiro é um verbo alternante e o segundo um verbo não alternante. Os exemplos em inglês são seguidos de traduções literais:

(3) The widow gave a million dollars to the university. A viúva deu um milhão de dólares para a universidade.

(4) The widow gave the university a million dollars. A viúva deu à universidade um milhão de dólares.

(5) The widow donated a million dollars to the university. A viúva doou um milhão de dólares para a universidade. 
(6) *The widow donated the university a million dollars.

A viúva doou à universidade um milhão de dólares.

Nos quatro experimentos relatados em Lombardi e Potter (1992), observou-se os efeitos de apresentação de um verbo bitransitivo não alternante como intruso potencial, após a leitura de uma sentença com verbo bitransitivo não alternante, porém sinônimo do intruso potencial. As pesquisadoras observaram que na intrusão de um verbo não alternante após apresentação de uma sentença com verbo alternante sinônimo em construções tais como (4) acima, durante a rememoração verbal de sentenças, as mesmas eram reconstruídas de modo que a gramaticalidade era mantida. Lombardi e Potter (1992) propõem que esses resultados são evidências de que tampouco uma representação sintática de sentenças recém lidas ou ouvidas permanece fixa na memorização imediata de sentenças. Alternativamente, as autoras propõem haver uma reconstrução das sentenças na memória de trabalho, a partir de exigências estruturais emergentes, tais como a ativação de um verbo cuja estrutura argumental é divergente daquela do verbo da sentença originalmente processada, como por exemplo os verbos give e donate, do inglês.

Portanto, o trabalho de Lombardi e Potter (1992) expande a hipótese da regeneração para as representações sintáticas. Esta expansão é avançada em Potter e Lombardi (1998), trabalho no qual são relatados três experimentos que exploram o efeito de priming sintático, ou seja, a tendência à reprodução de uma construção sintática à qual o falante foi recentemente exposto. Os resultados discutidos em Potter e Lombardi (1998) indicam a observação de priming sintático, exceto em situações em que a ativação de itens lexicais incompatíveis com a construção recente levam os falantes a reconstruir a representação sintática originalmente apresentada. Para a hipótese da regeneração, o efeito de priming sintático é paralelo à ativação recente de itens lexicais específicos, apontado por Potter e Lombardi (1990) como um mecanismo de suporte à acuidade da memorização imediata de sentenças. Através dele, prevê-se que uma construção sintática recentemente ativada na memória tenderá a ser retomada, salvo circunstâncias nas quais a regeneração da sentença se faça necessária também no nível da estrutura sintática.

Em síntese, a hipótese da regeneração propõe uma alternativa à hipótese de que a reprodução de sentenças a partir da memória de curta duração seja sustentada por 
uma representação mnemônica que é uma cópia idêntica, ou verbatim, da sentença anteriormente lida ou ouvida. Na hipótese da regeneração, propõe-se que o mecanismo de memorização de sentenças em memória de curta duração seja fundamentalmente o mesmo da produção de enunciados novos. Por outro lado, a hipótese da regeneração busca dar conta da aparente facilidade e a acurácia da rememoração de sentenças a partir da memória de curta duração propondo que essa facilidade seja função de três mecanismos principais (POTTER; LOMBARDI, 1998). 0 primeiro deles é a representação conceitual, ou semântica, da sentença em questão. 0 segundo é a reativação saliente, na memória de curta duração, das unidades lexicais presentes na sentença. 0 terceiro é a reativação igualmente saliente da estrutura sintática de uma sentença lida ou ouvida recentemente, ou seja, um mecanismo de priming sintático.

A hipótese da regeneração é compatível com modelos de processamento multifásico para produção de fala (LEVELT, 1989; PICKERING; BRANIGAN, 1998; LEVELT; ROELOFS; MEYER, 1999). Tais modelos preveem que a ativação de representações conceituais e semânticas dispara a ativação de unidades lexicais associadas a construções sintáticas específicas (lemas), que por sua vez dispara a ativação de representações fonológicas que darão suporte à implementação fonética de um enunciado. A hipótese da regeneração propõe que a memorização imediata seja apoiada por efeitos de ativação recente de representações lexicais e construções sintáticas, porém tendo por base uma representação conceitual e semântica, a partir da qual são ativados os mesmos mecanismos da produção de novos enunciados.

É importante salientar que os modelos de produção de fala supracitados preveem um mecanismo de codificação gramatical. Trata-se de um aspecto crítico tanto para a hipótese da regeneração quanto para o problema específico abordado neste trabalho, ou seja, a rememoração por bilíngues de sentenças em uma dada língua cuja estrutura gramatical pertence a sua outra língua. Tal mecanismo de codificação gramatical, nos modelos supracitados, se dá através da ativação de nódulos mnemônicos explicitamente relacionados a representações de cunho gramatical, tais como construções de realização de estrutura argumental. No modelo de Levelt, Roelofs e Meyer (1999), a associação entre esses nódulos de representações gramaticais a itens lexicais se dá no estrato lemático. Essa conceptualização captura a noção de que itens lexicais encapsulam informações gramaticais, noção esta compartilhada por diversos 
modelos da arquitetura da gramática (CHOMSKY, 1995; CULICOVER; JACKENDOFF, 2005; GOLDBERG, 1995; SAG et al., 2003). A Figura 1 abaixo ilustra esquematicamente o estrato lemático dos verbos give (dar) e donate (doar), da língua inglesa.

Figura 1: Modelo esquemático da ativação dos lemas give e donate, do inglês

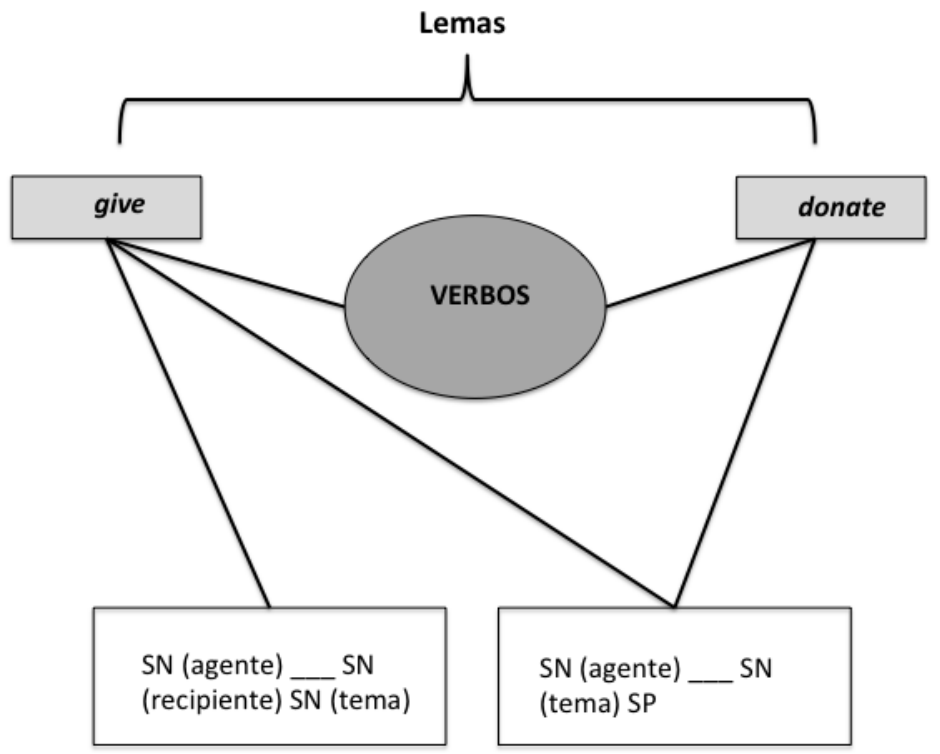

Tal como proposto em Pickering e Branigan (1998), cada lema estabelece ligações entre um dado item lexical e informações categoriais (a classe dos verbos, na Figura 1), que por sua vez associa-se a informações de traços morfológicos (no caso da Figura 1, tais traços incluiriam a possibilidade de marcação de tempo, aspecto, voz e concordância de pessoa e número, por exemplo). 0 lema encapsula também informações combinatoriais. Assim, segundo esta proposta, e tal como ilustrado esquematicamente na Figura 1, o estrato lemático do item lexical give no inglês possibilita a ativação a construção "sintagma nominal (SN) agente - verbo - sintagma nominal (SN) recipiente sintagma nominal (SN) tema", que dá suporte a uma sentença como (4) acima; assim como possibilita a ativação a construção "sintagma nominal (SN) agente - verbo sintagma nominal (SN) tema - sintagma preposicional (SP) com preposição + SN recipiente", que produz uma sentença como (3) acima, ou seja, a alternância dativa.

Por outro lado, como mostra a Figura 1, o item lexical donate só permite a ativação da construção "sintagma nominal (SN) agente - verbo - sintagma nominal (SN) tema - sintagma preposicional (SP) com preposição + SN recipiente". Nos experimentos relatados em Lombardi e Potter (1992) e Potter e Lombardi (1998), a configuração do 
estrato lemático desses dois verbos quase sinônimos na língua inglesa explica a regeneração da sentença nas circunstâncias de intrusão da ativação de donate na rememoração de uma sentença com give na alternância dativa.

A hipótese da codificação gramatical por ativação de estratos lemáticos durante a produção de fala oferece também um modelo do mecanismo subjacente aos efeitos de priming sintático. Tais efeitos podem ser explicados como permanência residual de ativação recente da informação combinatorial, o que levaria à tendência de uma dada construção sintática recém processada ser repetida com outro verbo, desde que esse novo verbo também seja um lema que compartilhe associação com a construção recém lida ou ouvida.

Tal hipótese tem sido produtiva em estudos que, como o presente trabalho, buscam investigar se as representações gramaticais das línguas dos bilíngues são integradas ou separadas. Hartsuiker, Pickering e Veltkamp (2004) propõem uma expansão da configuração do estrato lemático apresentada em Pickering e Brianigan (1998), nela incluindo um nódulo de especificação de código linguístico. Assim, para Hartsuiker, Pickering e Veltkamp (2004) sinônimos interlinguais, ou seja, itens lexicais que são traduções um do outro em duas línguas diferentes, podem encontrar-se armazenados integradamente na memória do bilíngue, uma vez que tais itens são marcados para uma língua específica. Segundo Hartsuiker, Pickering e Veltkamp (2004), uma vez havendo compartilhamento de nódulos combinatoriais por esses sinônimos interlinguais, ou seja, uma vez que eles ocorram em construções sintáticas compartilhadas nas duas línguas, há a possibilidade de priming sintático translinguístico. Em outras palavras, para esses autores, é possível que o processamento recente de uma sentença com uma estrutura sintática em uma língua leve à produção de sentença com a mesma estrutura sintática em outra língua. Esta hipótese é confirmada pelos dados do experimento de Hartsuiker, Pickering e Veltkamp (2004), com bilíngues do espanhol e do inglês, no qual os pesquisadores observaram priming sintático translinguísticos de sentenças na voz passiva.

Os resultados de Hartsuiker, Pickering e Veltkamp (2004) foram replicados com outros perfis de bilíngues e outras construções. Salamoura e Williams (2007) obtiveram resultados com bilíngues do grego e do inglês, através de experimentos de priming sintático translinguístico com construções bitransitivas. Os autores propõem a 
possibilidade de compartilhamento de estrutura sintáticas e detalhamentos de papéis temáticos na memória linguística bilíngue. Schoonbaert, Hartsuiker e Pickering (2007) relatam resultados semelhantes, nos quais o priming sintático translinguístico foi observado também com a construção bitransitiva, porém com bilíngues do holandês e do inglês. Bernolet, Hartsuiker e Pickering (2013) observaram efeitos de priming sintático translinguístico com bilíngues falantes de holandês e inglês, com alta proficiência em sua L2, porém com a alternância entre o genitivo saxônico e o genitivo preposicionado. Em conjunto, esses estudos sugerem a possibilidade de compartilhamento de construções sintáticas em um repositório mnemônico único na mente bilíngue.

É importante notar, entretanto, que esses estudos que apontam para um compartilhamento de representações sintáticas no processamento da linguagem por bilíngues são estudos nos quais a construção sintática em questão é licenciada em ambas as línguas faladas pelos participantes. Bernolet, Hartsuiker e Pickering (2013) sugerem que em teoria nada impediria que uma construção de apenas uma das línguas dos bilíngues fosse ativada em uma circunstância de produção de enunciados na outra língua. Porém, desconhecemos estudos nos quais esta hipótese foi explorada sistematicamente e em bases empíricas controladas. É a exploração desta hipótese que se busca no estudo ora relatado.

Entendemos que a hipótese da regeneração se apresenta como uma possibilidade promissora para colocar em teste a hipótese de que uma construção sintática de apenas uma das línguas de bilíngues pode ser ativada em uma circunstância de produção de enunciados na outra língua. A partir da hipótese da regeneração, podemos prever que a memorização imediata de uma sentença que simula em uma língua uma construção específica de outra seria facilitada caso os bilíngues tivessem acesso ao estrato lemático que dá suporte a essa construção. Por exemplo, como será detalhado abaixo, o lema verbal run (correr) do inglês associa-se tanto a uma construção sintática intransitiva quanto a uma construção sintática transitiva com leitura causativa, o que não ocorre em português. A hipótese por nós sugerida aqui é que seria possível a um bilíngue do português e do inglês ativar a construção sintática transitiva com leitura causativa (exclusiva do inglês) ao produzir enunciados com o verbo correr, em virtude da associação deste verbo do português com o verbo run, do inglês. 
As sessões subsequentes deste trabalho se dedicam exatamente ao relato do teste da hipótese de que uma construção de apenas uma das línguas dos bilíngues pode ser ativada na rememoração imediata de sentenças. Especificamente na próxima sessão, apresentaremos brevemente um contraste entre o inglês e o português, assim como alguns resultados de estudos psicolinguísticos sobre a compreensão de sentenças por bilíngues dessas duas línguas que lidaram com tal contraste, e explicitaremos hipóteses derivadas desses estudos sobre as implicações desse contraste para a memorização imediata de sentenças.

\section{A expressão de movimento induzido no inglês}

Na língua inglesa, há um tipo de construção causativa que é denominada por Levin (1993) de "alternância de movimento induzido". Segundo a autora, desta construção participa um subconjunto de verbos da língua inglesa cuja configuração semântica básica codifica conceituação de modo de movimento, sendo os verbos run (correr), jump (pular) e march (marchar) alguns exemplares. A construção em questão é referida como uma alternância porque nela verbos que ocorrem tipicamente como intransitivos passam a comportar-se transitivamente, transcorrendo-se portanto uma alternância de transitividade dos verbos que dela participam. A alternância de movimento induzido mapeia um argumento causador e um argumento agente do evento expresso pelo verbo a uma configuração sintática do tipo "SN 1 -verbo-SN2". Assim, a leitura obtida é a de que o sujeito sintático da oração assim produzida leva ou induz o objeto sintático da oração a mover-se do modo expresso pelo verbo.

A alternância de movimento induzido não é uma construção tipicamente lícita no português, uma vez que os verbos de modo de movimento da língua portuguesa não são configurados com a totalidade dos fatores semânticos necessários para a causativização, tal como demonstrado por Cambrussi (2009). A alternância de movimento induzido do inglês e sua restrição no português do Brasil são ilustradas nas sentenças (7) a (10) abaixo, nas quais os pares (7) e (9), e (8) e (10), são traduções literais: 
(7) The captain marched the soldiers to the camp.

(8) The psychologists ran the rat through the maze.

(9) *O capitão marchou os soldados para o acampamento.

(10) *Os psicólogos correram o rato pelo labirinto.

Por ser a alternância de movimento induzido com verbos de modo de movimento uma construção da língua inglesa não compartilhada pela língua portuguesa, ela se torna interessante para a investigação da especificidade do conhecimento linguístico de bilíngues do português e do inglês. Souza (2011) relata um estudo baseado em experimentos de julgamento de aceitabilidade, no qual foram replicados com falantes do português do Brasil e do inglês resultados anteriormente observados por Montrul (2001) com bilíngues do espanhol e do inglês, nativos do espanhol e do turco. Estes resultados apontam para a aprendizibilidade, em níveis de alta proficiência no inglês como L2, da alternância de movimento induzido.

Especificamente, Souza (2011) relata que falantes monolíngues do PB demonstraram acentuada tendência à rejeição de sentenças tais como (9) e (10), que forçam a alternância de movimento induzido do inglês para língua portuguesa, confirmando a anomalia da construção em língua portuguesa. Níveis de rejeição comparáveis foram verificados com bilíngues do PB-inglês de média proficiência na segunda língua, que sugere que estes bilíngues julgam essas sentenças em inglês em conformidade com a restrição gramatical de sua língua materna. 0 autor relata, ainda, julgamentos obtidos com monolíngues do inglês e com bilíngues do PB-inglês de alta proficiência. Contrariamente aos monolíngues do PB e aos bilíngues de menor proficiência, as sentenças com a alternância de movimento induzido foram amplamente julgadas como aceitáveis pelos falantes nativos do inglês e pelos bilíngues de maior proficiência. Em síntese, esses resultados sugerem que a restrição da língua portuguesa é transferida para a língua inglesa, mas não indefinidamente, uma vez que em estágios de maior proficiência na L2 os bilíngues do PB e do inglês não se diferenciam dos falantes nativos do inglês em relação à percepção de aceitabilidade de orações que instanciam a alternância de movimento induzido.

Souza (2012) relata um experimento no qual a mesma construção e seu contraste no PB e no inglês foram explorados, porém com foco no custo de processamento em tempo real que sentenças em inglês e sentenças em português (que simulavam a 
alternância de movimento induzido, portanto) têm para monolíngues de cada uma das línguas, e para bilíngues com níveis de proficiência diferentes. Tal experimento pautouse em uma tarefa de leitura auto-cadenciada. Os resultados apresentados pelo autor sugerem que a anomalia da alternância de movimento induzido em língua portuguesa associa-se a um custo de processamento elevado desta construção para monolíngues do PB e bilíngues do PB e do inglês com menor proficiência na L2, quando eles a processam no inglês. Essa situação foi discrepante dos resultados obtidos com a observação de monolíngues do inglês e bilíngues do PB e do inglês de maior proficiência, quando processaram a construção em inglês. Estes dois grupos apresentaram custo de processamento significativamente mais baixo que os dois grupos anteriores.

Todavia, o resultado que mais chama a atenção no estudo de Souza (2012) foi obtido na observação do processamento sentencial de um segundo grupo de bilíngues do PB e do inglês com alta proficiência na L2, porém que foram expostos a estímulos em português, ou seja, a sentenças que simulavam na língua materna dos bilíngues uma construção específica de sua L2. 0 custo de processamento das sentenças que forçavam para o português a alternância de movimento induzido do inglês para estes participantes não foi diferente do custo observado entre os monolíngues do inglês e dos bilíngues de alta proficiência ao processarem sentenças em inglês. Além disso, tal custo de processamento foi significativamente menor do que o observado entre os monolíngues do PB ao lerem as mesmas sentenças, e dos bilíngues do PB e do inglês de menor proficiência ao lerem sentenças em inglês. 0 autor interpreta tais observações como indicativas de que os bilíngues com maior proficiência afastaram-se da restrição de sua primeira língua o que sugere uma influência do bilinguismo sobre o desempenho na língua materna , e um indício de integração das representações das duas línguas.

Portanto, há indícios de que a alternância de movimento induzido, uma construção específica da língua inglesa, agramatical na língua portuguesa, tenha alguma ativação mesmo quando é a L1 que é processada por bilíngues do PB e do inglês com alto nível de proficiência na L2. As observações supracitadas sugerem tal ativação vestigial em tarefas de compreensão da linguagem. Entretanto, resta a verificação da amplitude desses prováveis efeitos do bilinguismo sobre o processamento da L1, e um aspecto a ser investigado é até que ponto ele pode ser detectado em tarefas de produção.

A hipótese da regeneração nos oferece um arcabouço teórico cujas previsões se 
articulam com o objetivo de investigação de possíveis efeitos de diferenciação dos bilíngues em relação aos monolíngues. 0 pressuposto de que na memorização imediata as sentenças são reconstruídas a partir de uma representação semântica, e não reproduzidas a partir de uma cópia mnemônica verbatim, acarreta que na ausência de disponibilidade de associação entre lema e construção, no âmbito do estrato lemático, a rememoração de uma sentença surgiria modificada, ou se daria com maior dificuldade, já que não teria como suporte a representação sintática apropriada.

A seguir relatamos o desenho de um estudo experimental que se pautou nestas considerações.

\section{Método}

0 presente estudo se baseou em uma análise de corpus de gravações orais obtidas através do experimento baseado em tarefa de memorização de sentenças relatado em Souza, Fernández e Guimarães (2012) e Fernández e Souza (no prelo). Nesta seção, serão detalhados aspectos deste experimento e, ao final, os procedimentos específicos da análise ora proposta.

\subsection{Participantes}

Participaram deste estudo três grupos de pessoas, agrupadas em função de perfis linguísticos diferenciáveis.

O primeiro grupo foi composto por 12 sujeitos monolíngues do inglês, estudantes universitários de uma instituição de ensino superior na cidade de Nova York, EUA. A média de idade deste grupo era 19,1 anos. Todos foram recrutados a partir de um sistema de chamadas para experimentos científicos da instituição, e sua participação rendeu-lhes créditos para a conclusão de uma disciplina básica de psicologia que compõe o currículo comum para estudantes de vários campos de conhecimento.

O segundo grupo e o terceiro grupo foram compostos por bilíngues do PB e do inglês, todos residentes na cidade de Nova York, EUA, e que foram avaliados quanto a sua proficiência da língua inglesa através de um questionário sobre sua história linguística e de auto-avaliação nas habilidades de leitura, escrita, compreensão oral e 
fala na L2, e também por um teste de tamanho de vocabulário em inglês, o Vocabulary Levels Test ou VLT (NATION, 1990). O questionário de auto-avaliação gerava escores médios de 1 (muito pouco) e 5 (muito bem). 0 desempenho no VLT foi apurado com base no número total de acertos, o que gerou escores entre 0 e 90 pontos. Todos os participante bilíngues tinham no mínimo nível superior iniciado e foram recrutados por amostragem de conveniência. Somente um participante bilíngue tinha vínculo como estudante da instituição dos participantes monolíngues do inglês.

Os dados do questionário revelaram que todos os participantes bilíngues iniciaram a aprendizagem do inglês após os sete anos de idade, no Brasil. Igualmente, todos mantinham laços sociais com falantes do português e usavam a língua cotidianamente para várias atividades. Nenhum desses participantes se caracterizava como tendo perdido habilidades em sua L1.

Um grupo de bilíngues foi composto por 11 participantes cujo escore médio no VLT foi de 47,3 acertos, e o escore médio no questionário de auto-avaliação foi de 3,5. A média de idade dos participantes deste grupo foi de 29 anos de idade. Este grupo será doravante denominado grupo de "bilíngues com menor proficiência".

O outro grupo de bilíngues foi composto por 13 participantes cujo escore médio no VLT foi de 80,4 acertos, e o escore médio no questionário de auto-avaliação foi de 4,8. A média de idade dos participantes deste grupo foi de 35 anos de idade. Este grupo será doravante denominado grupo de "bilíngues com maior proficiência".

\subsection{Materiais}

Dois conjuntos de materiais foram construídos, um em inglês e outro em português. Neste conjunto, havia 18 sentenças alvo e 18 sentenças distratoras. As sentenças alvo eram divididas em três grupos configurados a partir da construção que instanciavam. Todas as sentenças alvo tinham a forma de superfície " $\mathrm{SN}_{1}$-verbo-SN 2 -SP", sendo o primeiro $\mathrm{SN}_{1}$ sempre modificado por um adjetivo e o $\mathrm{SN}$ sempre formado apenas por um determinante e o núcleo. Os sintagmas preposicionais eram formados pela preposição e um SN, também formado apenas por um determinante e o núcleo.

O primeiro grupo era formado por seis sentenças que instanciavam a alternância de movimento induzido com verbos de modo de movimento. Tratava-se, portanto, de 
sentenças lícitas na versão em inglês, mas anômalas na versão em português. Os verbos usados foram run/correr, walk/andar, fly/voar, swim/nadar, jump/pular e march/ marchar. Denominamos este grupo de "modo de movimento". As sentenças (11) e (12) abaixo exemplificam uma sentença do grupo "modo de movimento" em inglês e outra em português, respectivamente.

(11) The behavior researcher ran her mouse through the box.

(12) *0 psicólogo experimental correu suas cobaias em um labirinto.

O segundo grupo, também com seis sentenças, era formado por verbos intransitivos tanto em português quanto em inglês. Portanto, tratava-se de verbos que não admitiriam um sintagma nominal como complemento, o que tornava as sentenças agramaticais nas duas línguas. Denominamos este grupo de "pseudocausativas". Os verbos usados para as sentenças pseudocausativas foram laugh/rir, appear/aparecer, speak/falar, play/brincar, fall/cair, arrive/chegar. As sentenças (13) e (14) são exemplos deste grupo.

(13) *The organic farmer fell the apple from the tree.

(14) ${ }^{*} O$ advogado cansado caiu os documentos da mesa.

O último grupo foi composto por seis sentenças com verbos de mudança de estado. Trata-se de verbos que alternam naturalmente a transitividade em ambas as línguas, pois podem acarretar tanto uma leitura causativa quanto uma leitura de voz média. Denominamos este grupo de "mudança de estado". As sentenças do grupo mudança de estado, exemplificadas em (15) e (16), são licenciadas nas duas línguas.

(15) The young dancers dried their dresses at the theater.

(16) As jovens atrizes secaram suas saias no teatro.

\subsection{Procedimentos}

A tarefa cuja execução era solicitada aos participantes envolvia a leitura silenciosa de sentenças, seguida imediatamente por de sua rememoração oral sem acesso à versão escrita, e finalmente de uma segunda sentença, sobre a qual os 
participantes tinham que decidir se se tratava da mesma sentença anteriormente lida e repetida oralmente, ou não. Havia, portanto, um contexto claro de memorização na tarefa.

Para cada fase dos itens, ou seja, a leitura silenciosa, a repetição oral da sentença e a decisão sobre a identidade da sentença lida e repetida com uma segunda sentença, havia um teto de 9 segundos. Assim, os participantes eram informados que a tarefa exigiria atenção e rapidez. A fase da leitura silenciosa poderia ser interrompida pelo participante através do acionamento da tecla "espaço" de um teclado de computador. A fase da reprodução oral, durante a qual não havia acesso visual a nenhum texto escrito, não podia ser interrompida, assim havia a possibilidade de tempo de espera, caso o participante repetisse a sentença em menos tempo que o teto temporal. A fase da decisão era interrompida pelo acionamento das teclas designadas para a resposta "sim" (segunda sentença igual à primeira) ou "não" (segunda sentença diferente da primeira).

O experimento foi executado individualmente por cada participante, em um computador portátil do padrão IBM ao qual foi acoplado um headset com microfone para a gravação das memorização imediata das sentenças. Os participantes monolíngues do inglês realizavam a tarefa apenas em sua língua materna, e os bilíngues nas duas línguas, sempre inicialmente na língua portuguesa. 0 programa DMDX ${ }^{1}$ (FOSTER; FOSTER, 2003) foi usado para a apresentação e randomização dos itens em cada sessão experimental, assim como para o registro das respostas motoras e orais. As respostas orais foram registradas em formato $\mathrm{mp} 3$.

\subsection{Análise}

No presente estudo, as gravações da reprodução oral após memorização imediata das sentenças dos três tipos de construção acima descritos foram analisadas. Especificamente, buscou-se a identificação de ocorrência de pausas nesta reprodução. A ocorrência de pausas é um indicador de disfluência que pode refletir sobrecarga cognitiva no processamento da fala (SEGALOWITZ, 2010), porém também estágios desenvolvimentais da aquisição de uma segunda língua não convergentes com a prosódia de falantes nativos da L2 (RIAZANTSEVA, 2001). Por ser o foco do presente

\footnotetext{
${ }^{1}$ Distribuído gratuitamente. http://www.u.arizona.edu/ kforster/dmdx/dmdx.htm.
} 
estudo um aspecto estritamente relacionado ao processamento da linguagem por bilíngues, e não um aspecto da aquisição de L2 em si, optou-se por realizar-se as análises ora descritas apenas com os dados de desempenho na língua materna dos bilíngues, uma vez que não havia evidências sugestivas de que a mesma se encontrava em processo de erosão, além de ser a língua dos estímulos que eliciaram os dados.

Por serem as sentenças relativamente curtas, definimos períodos iguais ou maiores que 200 milissegundos como pausas relevantes, por gerarem interrupção perceptível no fluxo da fala contínua. A segmentação dos arquivos de áudio e o cálculo da duração dos períodos de silêncio foram realizados através do programa Speech Analyzer², da Summer Institute of Linguistics, Inc.

Após a extração de todas as ocorrências das pausas relevantes para cada um dos três tipos de sentenças alvo, elas foram agrupados em função da localização de sua ocorrência na sentença. Definimos duas regiões sentenciais críticas, uma pré-verbal e outra pós-verbal. A região pré-verbal englobou o $\mathrm{SN}_{1}$ (determinante-modificadornúcleo) e o verbo, e a região pós-verbal englobou o $\mathrm{SN}_{2}$ (determinante-núcleo) e o $\mathrm{SP}$ (preposição-determinante-núcleo nominal). Na Figura 2 abaixo há uma apresentação esquemática da divisão da sentença (12), acima.

Figura 2: Representação das regiões pré e pós-verbal

\section{Região Pré-verbal}

o psicólogo experimental correu

\section{Região Pós-verbal} suas cobaias em um labirinto

Dois critérios guiaram essa definição. 0 primeiro deles levou em consideração a distribuição de ocorrências de palavras com carga semântica saliente, sendo três na região pré-verbal (substantivo, adjetivo e verbo) e três na região pós-verbal (substantivo, preposição e substantivo). O segundo critério foi o fato de que especificamente na alternância de movimento induzido e nas sentenças pseudocausativas, a região pré-verbal contem em si a construção "SN-verbo", ativada no estrato lemático dos verbos desses dois tipos de sentenças, tanto em português quanto dos verbos .

\footnotetext{
2 Distribuído gratuitamente. http://www-01.sil.org/computing/sa/.
} 
Assim, com base na hipótese da regeneração, esperávamos observar um efeito facilitatório para memorização imediata da região pré-verbal das sentenças do tipo "modo de movimento" e do tipo "pseudocausativa" por essa região apoiar-se em uma representação sintática ativada pelos lemas verbais. A região pós-verbal, por outro lado, não teria sua memorização apoiada pelas construções sintáticas ativadas por esses lemas verbais, o que teoricamente as tornaria sua memorização imediata menos estável.

Passemos, então, à descrição dos resultados observados e sua discussão.

\section{Resultados e discussão}

A partir dos arquivos de áudio com as gravações dos três grupos de participantes, foram separadas todas as ocorrências de pausas maiores do que 200 milissegundos, nos três tipos de sentenças alvo do presente estudo. Observou-se, então, a região sentencial dessas ocorrências de acordo com o critério supracitado, ou seja, foram contadas as pausas que aconteciam até o verbo, assim como foram contadas as pausas que aconteciam após o verbo.

A frequências contadas foram submetidas a tratamento estatístico inferencial através do teste do chi-quadrado $\left(\chi^{2}\right)$. Genericamente, houve um número relativamente pequeno de pausas maiores que $200 \mathrm{~ms}$, o que pode ser interpretado como indicativo de que a tarefa de memorização imediata planejada para este estudo não apresentou grau elevadíssimo de dificuldade para os participantes. 0 teste do $\chi^{2}$ não deve ser empregado quando as frequências esperadas são menores que 5 ocorrências. Nos dados ora relatados, as frequências esperadas variaram entre 7,5 e 13,5. Porém, não obstante a adequação de nossos dados ao critério mínimo para a confiabilidade da significância do teste estatístico, optamos por considerar a significância exata das estatísticas obtidas (teste exato de Fisher), e não a significância assintótica, que geralmente é considerada quando o teste do chi-quadrado é realizado com amostras maiores e que permitem maior poder estatístico para o teste (SHIELDS, 2013). 0 grau de significância foi $\alpha=0,05$. As análises foram realizadas com o programa SPSS versão 21, da IBM, e os gráficos foram construídos com o programa Excel, da Microsoft. 
O Gráfico 1 apresenta visualmente as observações das pausas ocorridas durante a rememoração verbal das sentenças lidas pelos falantes monolíngues do inglês americano.

Gráfico 1: Distribuição de pausas de 200ms ou mais na região pré-verbo e na região pós-verbo de cada tipo de sentença, dos falantes do inglês monolíngues

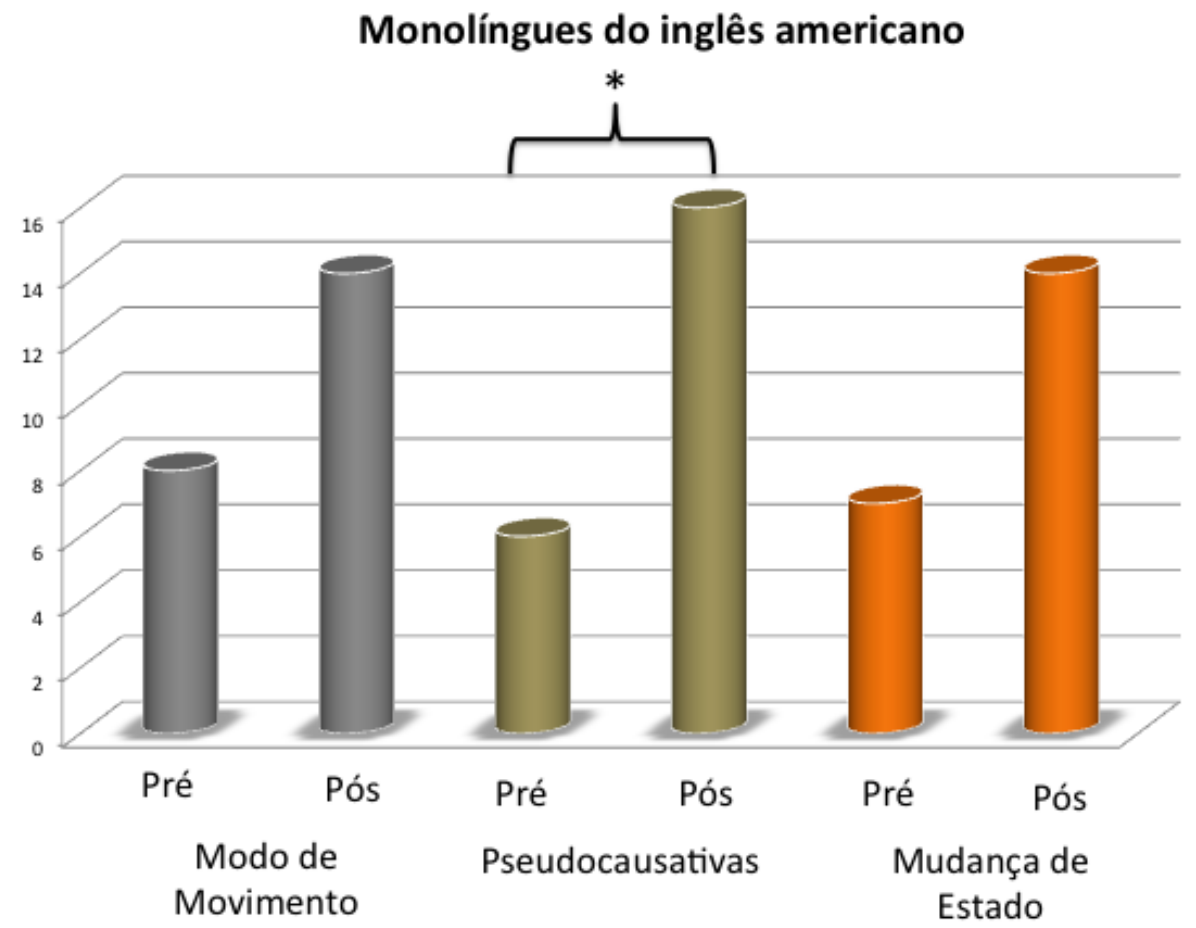

Tal como mostrado no Gráfico 1, os participantes monolíngues falantes do inglês americano revelaram uma tendência geral a realizar mais pausas na região pós-verbo, independentemente do tipo de sentenças rememorada verbalmente. Nas sentenças com verbos de modo de movimento, ocorreram 8 pausas relevantes antes do verbo e 14 após, não tendo essa diferença atingido significância estatística $\left(\chi^{2}=1,64(G L=1), p=0,29\right.$ (significância exata)). Ocorreram 7 pausas relevantes antes do verbo e 14 após o verbo nas sentenças com verbos de mudança de estado, diferença esta não significativa $\left(\chi^{2}=2,33\right.$ ( $\left.G L=1\right), p=0,19$ (significância exata)). A diferença entre o número de pausas iguais ou maiores a 200 milissegundos nas duas regiões de interesse (pré-verbo $=6$, pós-verbo $=16$ ) para as sentenças pseudocausativas foi mais acentuada entre os falantes monolíngues do inglês americano, sendo tal diferença estatisticamente significativa $\left(\chi^{2}=4,54(\mathrm{GL}=1), \mathrm{p}=0,05\right.$ (significância exata)). 
O Gráfico 2 representa os resultados das observações com os bilíngues de menor proficiência.

Gráfico 2: Distribuição de pausas de 200ms ou mais na região pré-verbo e na região pós-verbo de cada tipo de sentença, dos falantes bilíngues com menor proficiência

\section{Bilíngues de menor proficiência}

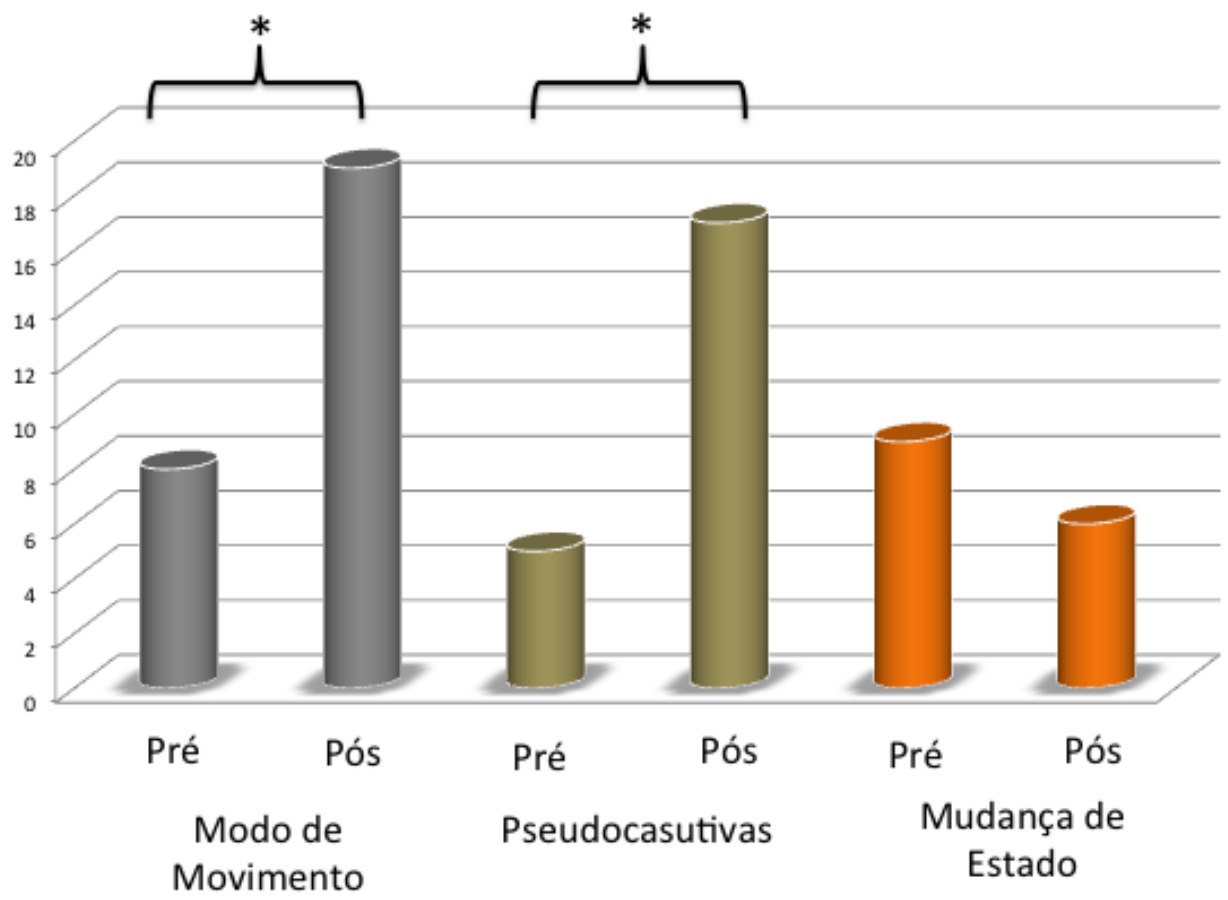

A inspeção da informação visual do Gráfico 2 revela que entre participantes bilíngues com menor proficiência houve um paralelo entre a distribuição das pausas relevantes observada nas sentenças com a alternância de modo de movimento (préverbo $=8$; pós-verbo $=19$ ) e as sentenças pseudocausativas (pré-verbo $=5$; pós-verbo= 17). A análise das diferenças observadas em ambos os tipos de sentenças com o teste do chi-quadrado produziu, respectivamente, os resultados $\left(\chi^{2}=4,48\right.$ (GL=1), $p=0,05$ (significância exata)) e $\left(\chi^{2}=6,54 \quad(\mathrm{GL}=1), \mathrm{p}=0,02\right.$ (significância exata)). Portanto, verificaram-se diferenças estatisticamente significativas nas distribuições das pausas para esses dois tipos de sentenças. Por outro lado, um padrão inverso ocorreu com as sentenças causativas com verbos de mudança de estado, nas quais pausas de $200 \mathrm{~ms}$ ou mais foram um pouco mais frequentes na região pré-verbo, sem entretanto ser tal diferença significativa $\left(\chi^{2}=6,00(\mathrm{GL}=1), \mathrm{p}=0,61\right.$ (significância exata)). 
O Gráfico 3 sintetiza as observações realizadas com os bilíngues de maior proficiência.

Gráfico 3: Distribuição de pausas de 200ms ou mais na região pré-verbo e na região pós-verbo de cada tipo de sentença, dos falantes bilíngues com maior proficiência

\section{Bilíngues de maior proficiência}

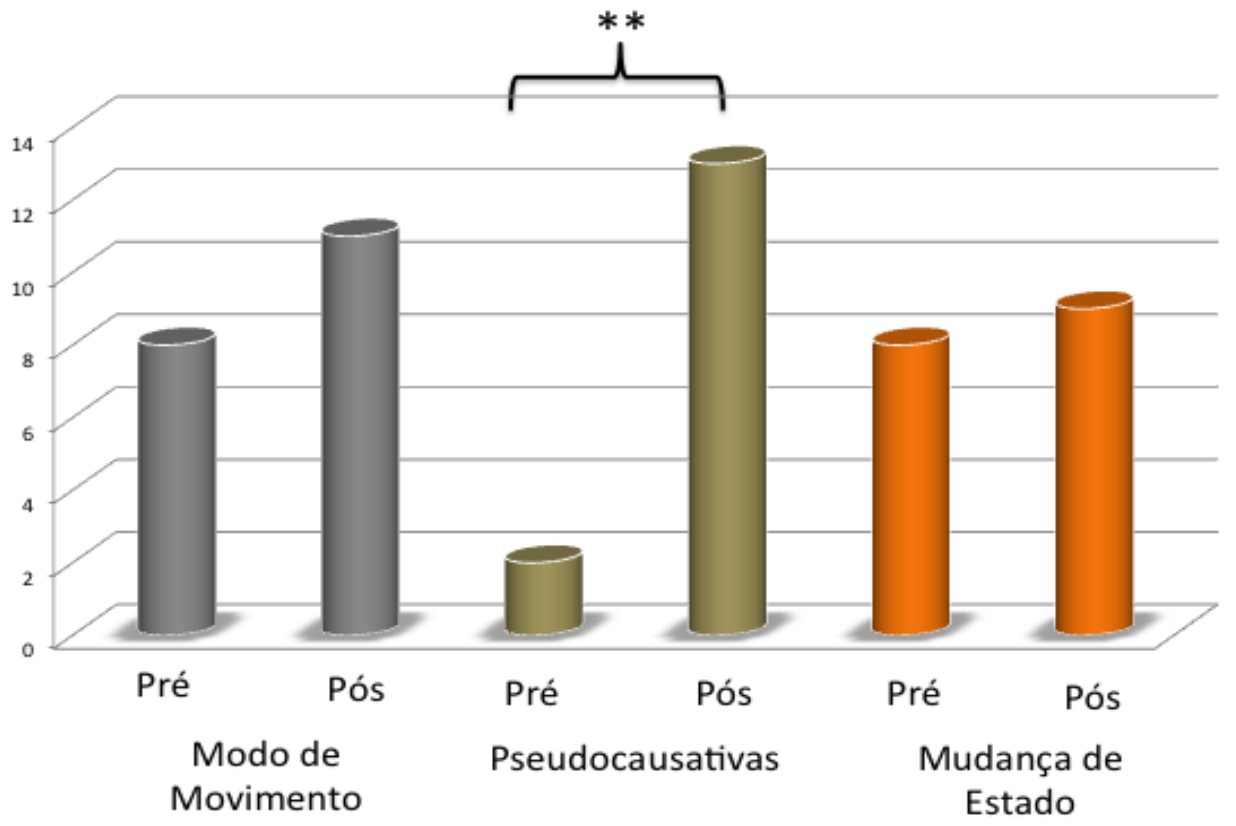

O Gráfico 3 mostra que o padrão observado entre participantes bilíngues teve um certo paralelismo com o padrão observado entre os falantes monolíngues do inglês, com mais pausas relevantes na região pós-verbo dos três tipos de sentenças analisados. Contudo, entre este grupo observou-se uma tendência acentuada à concentração das pausas pós-verbo nas sentenças pseudocausativas (pré-verbo $=2$; pós-verbo $=13$ ) sendo a diferença da distribuição de pausas entre as duas regiões estatisticamente significativa $\left(\chi^{2}=8,07(G L=1), p=0,007\right.$ (significância exata)). Por outro lado, foram menos salientes as diferenças de distribuição das pausas relevantes observada nas sentenças com a alternância de modo de movimento (pré-verbo= 8; pós-verbo=11), não sendo tal diferença significativa $\left(\chi^{2}=0,47(G L=1), p=0,64\right.$ (significância exata)). Por sua vez, as sentenças causativas com verbos de mudança de estado eliciaram praticamente o mesmo número de pausas relevantes nas duas regiões sentenciais, pré-verbo $=8$ e pósverbo $=9, \chi^{2}=0,59(\mathrm{GL}=1), \mathrm{p}=1,0$ (significância exata). 
Observamos, portanto, que especialmente entre os bilíngues do presente estudo o padrão de dificuldade com a memorização imediata de sentenças seguiu o que é previsível a partir da consideração do estatuto gramatical da alternância de modo de movimento, e também dos estudos anteriores com a compreensão de sentenças.

Em outras palavras, os bilíngues de menor proficiência parecem permanecer com a restrição gramatical de sua L1, que pode ser interpretada como não admitindo a ativação de uma construção do tipo $\mathrm{NP}_{1}$-Verbo- $\mathrm{NP}_{2}$ no estrato lemático de verbos de modo de movimento como "correr" e "pular". Assim, sentenças com verbos de modo de movimento em sintaxe transitiva geraram episódios de disfluência, aferidos através do número de pausas após o verbo, tão frequentes quanto sentenças pseudocausativas, absolutamente agramaticais. Por outro lado, a frequência das pausas na região não apoiada pelo estrato lemático dos verbos foi maior do que a observada em sentenças causativas com verbos de mudança de estado, para os quais a ocorrência de um sintagma nominal como objeto direto é totalmente natural nas duas línguas às quais os bilíngues são expostos.

Por outro lado, os bilíngues com alta proficiência na L2 não mostraram dificuldades especialmente acentuadas na reprodução oral da área pós-verbal das sentenças com verbos de modo de movimento, mas sim nas sentenças pseudocausativas. Quanto a esta observação, é possível dizer que eles se aproximaram do desempenho observado entre os monolíngues do inglês, para quem somente para as sentenças pseudocausativas foi observada significância estatística na diferença entre a frequência de pausas da região pré-verbal e pós-verbal, com a segunda maior que a primeira. No tocante ao que aconteceu com as sentenças de modo de movimento, é possível dizer que os bilíngues com maior proficiência observados neste estudo distanciaram-se da restrição da gramática de sua $L 1$.

É importante notar que a distribuição com pausas mais frequentes na região pósverbal em associação ao estatuto de gramaticalidade da construção é mais saliente nas observações com os participantes bilíngues que entre os participantes monolíngues. Uma hipótese para explicar este padrão é que os bilíngues podem ter, durante o processamento, um nível de ativação subliminar de nódulos mnemônicos de construções de realização de estrutura argumental de uma língua diferente daquela na qual se dá processamento linguístico em curso, em virtude de sua experiência com mais 
de uma língua. Esta ativação subliminar pode acarretar uma alocação de recursos atencionais maior para a estrutura argumental dos verbos no processamento. Isto viria ao encontro da existência de representações construcionais ativadas no estrato lemático, o que foi previsto para a região pré-verbal tanto das sentenças do tipo modo de movimento como do tipo pseudocausativas, engendrando um efeito de facilitação da rememoração dessa área. Dentro desta hipótese, a diferença entre os bilíngues de maior e de menor proficiência seria a força da ativação dos nódulos mnemônicos do estrato lemático, possivelmente maior no primeiro grupo de bilíngues, em virtude de sua maior competência na L2.

\section{Conclusão}

O presente trabalho teve por objetivo explorar a possibilidade de integração de representações linguísticas das línguas faladas por bilíngues em tarefas nas quais o processamento linguístico dá suporte à produção. Os resultados de um experimento de memorização de sentenças foram sugestivos de que há a possibilidade de ativação de uma construção sintática de uma língua específica quando o bilíngue encontra-se processando uma outra língua. Porém, os resultados obtidos sugerem, em conformidade com estudos como Bernolet, Hartsuiker e Pickering (2013) e Souza (2012), que tal possibilidade é modulada pelo nível de proficiência do bilíngue na língua à qual pertence a construção específica.

As observações relatadas neste trabalho estão em conformidade com a hipótese da regeneração, que prevê que a memorização imediata de sentenças se dá através da produção de uma representação sentencial na memória de trabalho a partir da representação sintática. Assim, a partir dos mecanismo de suporte à memorização imediata de sentenças modelado por esta hipótese, é possível prever que haverá efeitos de facilitação da memorização de um sentença com estrutura sintática específica de uma língua durante o processamento da outra, caso a arquitetura de representações linguísticas dos bilíngues permita a integração de representações interlinguísticas. Os dados aqui discutidos apontam, precisamente, para uma arquitetura desta natureza. Além disso, eles dão testemunho de que tarefas de memorização imediata de sentenças 
podem fornecer um paradigma experimental útil na exploração deste problema de pesquisa.

Não obstante, os resultados ora apresentados são limitados em virtude de terem se apoiado em dados relativamente pouco numerosos, a ocorrência de pausas na produção de fala. Apesar do conjunto de dados ter sido suficiente para tratamento estatístico inferencial, o poder dos testes estatísticos empregado, definido como a capacidade efetiva de rejeição da hipótese nula de um teste de hipótese (DANCEY; REIDY, 2006), é limitado. Assim, uma perspectiva de prosseguimento ao trabalho ora relatado seria a sua replicação com amostras de participantes grandes o bastante para que haja aumento do número de observações de eventos de disfluência relacionados a pausas, ou alternativamente o exame de outras características da fala produzida, tal como elementos prosódicos, que possam ser marcadores de ônus cognitivo durante o processamento da fala.

\section{Referências}

BARTOLOTTI, J.; MARIAN, V. Bilingual memory: structure, access, and processing. In J. Altarriba \& L. Isurin (orgs.). Memory, Language and Bilingualism. Cambridge: Cambridge University Press, 2013.

BERNOLET, S.; HARTSUIKER, R.; PICKERING, M. From language-specific to shared syntactic representations: The influence of second language proficiency on syntactic sharing in bilinguals. Cognition, v. 127, n. 3, p. 287-306, 2013.

CAMBRUSSI, M. F. A Alternância Causativa de Verbos Inergativos no Português Brasileiro. Tese de Doutorado. Florianópolis: Universidade Federal de Santa Catarina, 2009.

CHOMSKY, N. The Minimalist Program. Cambridge, MA: The MIT Press, 1995.

CULICOVER, P.; JACKENDOFF, R. Simpler Syntax. Oxford/New York: Oxford Universiy Press, 2005.

DANCEY, C.; REIDY, J. Estatística sem Matemática para Psicologia. 3a Edição. Porto Alegre: Artmed, 2006.

FERNÁNDEZ, E. M.; SOUZA, R. A. Walking bilinguals across language boundaries: on-line and off-line techniques. In R. Heredia, J. Altarriba, \& A. B. Cieslicka (orgs.), Methods in bilingual reading comprehension research. Springer, no prelo. 
FORSTER, K.; FORSTER, J. DmDx: A Windows display program with millisecond accuracy. Behavior Research Methods Instruments and Computers, v. 35, n. 1, p. 116-124, 2003.

GOLDBERG. A. Constructions: A Construction Grammar Approach to Argument Structure. Chicago: University of Chicago Press, 1995.

HARTSUIKER, R.; PICKERING, M.; VELTKAMP, E. Is syntax separate or shared between languages? Cross-linguistic syntactic priming in Spanish-English bilinguals. Psychological Science, v. 15, n. 6, p. 409-414, 2004.

LEVELT, W. Speaking: From Intention to Articulation. Cambridge, MA: The MIT Press, 1989.

LEVELT, W; ROELOFS, A.; MEYER, A. A theory of lexical access in speech production. Behavioral and Brain Sciences, v. 22, n. 1, p. 1-38, 1999.

LEVIN, B. English Verb Classes and Alternations: A Preliminary Study. Chicago: University of Chicago Press, 1993.

LOMBARDI, L.; POTTER, M.C. The regeneration of syntax in short term memory. Journal of Memory and Language, v. 31, n. 6, p. 713-733, 1992.

MONTRUL, S. Agentive verbs of manner of motion in Spanish and English as second languages. Studies in Second Language Acquisition, v. 23, n. 2, p. 171-206, 2001.

NATION, I. P. Teaching and Learning Vocabulary. Boston, MA: Heinle \& Heinle, 1990.

PICKERING, M.; BRANIGAN, H. The representation of verbs: Evidence from sytactic priming in language production. Journal of Memory and Language, v. 39, n. 4, p. 633-651, 1998.

POTTER, M. C.; LOMBARDI, L. Regeneration in the short-term recall of sentences. Journal of Memory and Language, v. 29, n. 6, p. 633-654, 1990.

POTTER, M. C.; LOMBARDI, L. Syntactic priming in the immediate recall of sentences. Journal of Memory and Language, v. 38, n. 3, p. 265-282, 1998.

RIAZANTSEVA, A. Second language proficiency and pausing. A study of Russian speakers of English. Studies in Second Language Acquisition, v. 23, n. 4, p. 497-526, 2001.

SAG, I.; WASOW, T.; BENDER, E. M. Syntactic Theory - A Formal Introduction $\left(2^{\text {nd }}\right.$ Edition). Stanford, CA: CSLI Publications, 2003.

SALAMOURA, A.; WILLIAMS, J. Processing verb argument structure across languages: Evidence for shared representations in the bilingual lexicon. Applied Psycholinguistics, v. 28, n. 4, p. 627-660, 2007. 
SCHOONBAERT, S.; HARTSUIKER, R.; PICKERING, M. The representation of lexical and syntactic information in bilinguals: Evidence from syntactic priming. Journal of Memory and Language, v. 56, n. 2, p. 153-171, 2007.

SHIELDS, A. Discovering Statistics Using IBM SPSS Statistics. $4^{\text {th }}$ Edition. London: Sage Publications, 2013.

SOUZA, R. A. Argument structure in L2 acquisition: Language transfer re-visited in a syntax and semantics perspective. Ilha do Desterro, n. 60, p. 153-188, 2011.

SOUZA, R. A.; FERNÁNDEZ, E. M.; GUIMARÃES, M. P. Shared argument structure among bilinguals: Evidence from sentence reading and recall. Trabalho apresentado no TwentyFifth Annual Conference on Human Sentence Processing. Nova York: City University of New York, 2012 (Resumo estendido disponível em http://cuny2012.commons.gc. cuny.edu/files/2012/03/2012 booklet post-print.pdf]

SOUZA, R. A. Two languages in one mind and the online processing of causatives with manner-of-motion verbs. Revista Virtual de Estudos da Linguagem, v. 10, n. esp. 6, p. 220239, 2012.

VON ECKARDT, B.; POTTER, M.C. Clauses and the semantic representation of words. Memory and Cognition, v. 13, n. 4, p. 371-376, 1985.

Recebido em março de 2014.

Aceito em junho de 2014. 